\title{
Changes in Chest Radiograph After Aortic Valve Replacement
}

\author{
M. S. GOTSMAN, W. BECK, C. N. BARNARD, AND V. SCHRIRE \\ From the Cardiac Clinic, the Departments of Medicine and Surgery, the University of Cape Town, \\ and the Cardiovascular-Pulmonary Research Group, supported in the Department of Medicine \\ by the Council for Scientific and Industrial Research, Cape Town, South Africa
}

Aortic valve replacement carries a low operative mortality and produces dramatic relief of clinical disability.

The older techniques of blind valvotomy (Bailey et al., 1950; Brock, 1954, 1957), débridement, or cusp replacement with prosthetic materials (Bahnson et al., 1960) have been disappointing (McGoon and Moffitt, 1963) and have been superseded by valve replacement with a caged prosthesis (McCord et al., 1962; Barnard, Schrire, and Goosen, 1963; Schrire and Barnard, 1966); or homograft valves from a donor (Ross, 1962, 1964; Barratt-Boyes, 1964).

The long-term results of aortic valve replacement have been gratifying. Haemodynamic studies undertaken one year after operation have shown that the University of Cape Town lenticular prosthesis is competent and durable and produces only mild obstruction to left ventricular emptying (Beck, Barnard, and Schrire, 1966).

There are few reports of the long-term results of valve replacement and the over-all changes in the dilated or hypertrophied heart, though recent reviews have appeared from Lewis et al. (1966), Rastelli, Kincaid, and Kirklin (1966), and Björk and Cullhed (1967). We have, therefore, studied the changes in the chest $x$-ray film before and one year after aortic valve replacement to determine the effects of operation on cardiac enlargement and the radiological signs of pulmonary venous hypertension.

\section{Patients and Methods}

Studies were made on 28 patients in whom the aortic valve was replaced by a University of Cape Town lenticular prosthesis and who were followed for a period of at least one year after operation. Patients who did not

Received June 2, 1967. survive for one year or who did not have acceptable radiological studies have not been included.

The patients were divided into three clinical groups. Group A consisted of 12 patients, aged 16-61 years, with dominant aortic incompetence: due to syphilis in 3, acute bacterial endocarditis in 1 , and to rheumatic fever in the remaining $8 ; 4$ of the latter had an antecedent episode of subacute bacterial endocarditis. One patient had significant mitral valve disease. They all had grade 3/4 disability (Schrire et al., 1955), usually with conspicuous left ventricular failure. Operation was not undertaken for severe incompetence with minimal symptoms.

Group B consisted of 7 patients, aged 31-63 years, with severe calcific aortic stenosis. Six had trivial incompetence. One had severe systemic hypertension and another had mild mitral stenosis. Two had a history of previous rheumatic fever. Operation was undertaken only for severe symptoms-recurrent syncope, angina pectoris, or acute episodes of left ventricular failure.

Group C consisted of 7 patients, aged 33-58 years, with chronic rheumatic heart disease and mixed aortic valve stenosis and incompetence. Three had additional mitral valve disease and one in atrial fibrillation needed a mitral valvotomy. Patients who needed replacement of both aortic and mitral valves have not been included in this study.

Pre-operative cardiac catheterization with selective aortography and left ventriculography were undertaken as routine procedures, and confirmed the presence of severe valve disease, usually with compromised left ventricular function. Three patients with aortic incompetence were so ill that they required emergency valve replacement, and it was felt that pre-operative catheterization was not justified. Post-operative investigation was undertaken in 11 patients.

The surgical management has been described (Barnard et al., 1963; Schrire and Barnard, 1966).

Radiological Methods. Chest radiography in the postero-anterior and lateral positions, using a standard 6-foot tube-film distance, taken before and one year 


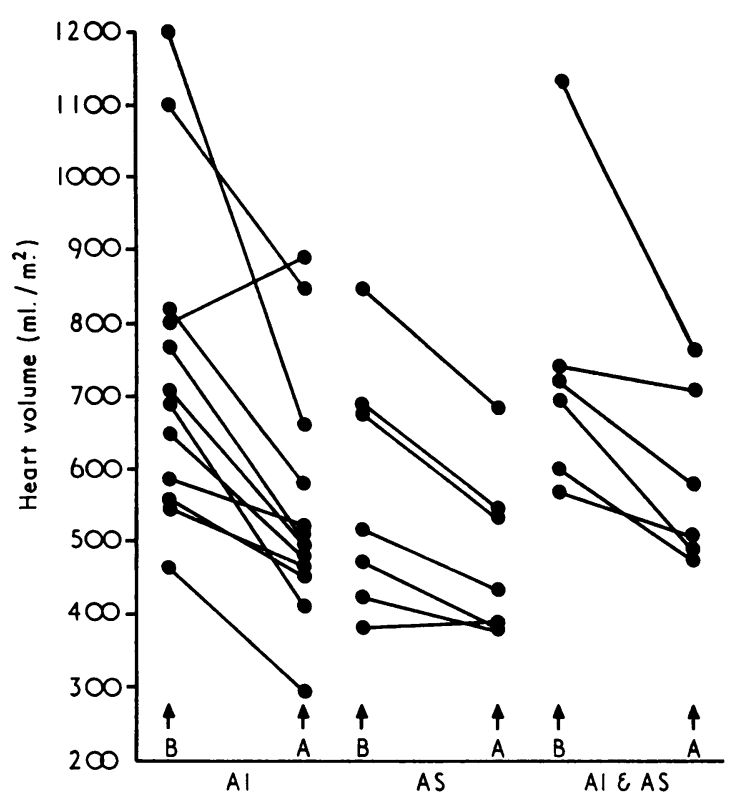

FIG. 1.-Change in heart volume after aortic valve replacement. Patients classified according to text $(B=$ before; $A=$ after). The greatest improvement was observed in patients with aortic incompetence where valve replacement reduced the volume overload of the left ventricle. Improvement was also noted in patients with pure aortic stenosis and heart failure who had enlarged hearts before operation.

after valve replacement, were assessed and compared. Accepted methods of measuring heart volume and cardiothoracic ratio and of assessing individual chamber enlargement and the pulmonary vascular and paren-

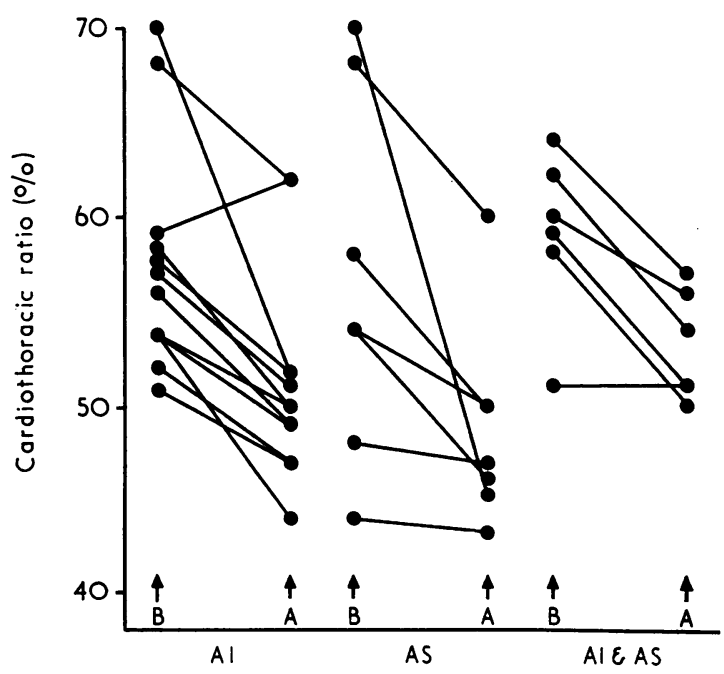

FIG. 2.-Change in cardiothoracic ratio after aortic valve replacement. chymal pattern were used and have been described in detail elsewhere (Liljestrand et al., 1939; Viamonte, Parks, and Barrera, 1962; Simon, 1963; Evans and Carpenter, 1965; Gotsman et al., 1967).

\section{RESULTS}

The changes in heart volume and cardiothoracic ratio are shown in Fig. 1 and 2. Patients in Group A (aortic incompetence) had the largest hearts before operation. The heart volume in this group was related to the pre-operative end-diastolic pressure in the left ventricle. After operation these patients showed the greatest reduction in heart volume (Fig. 3). Improvement started immediately after operation but continued during the subsequent year, and still further improvement was observed in the subsequent 2 years (Fig. 4).

A large heart before operation was unusual in patients with pure aortic stenosis (Group B) unless associated with severe left heart failure, so that only slight changes in volume were observed after operation (Fig. 5 and 6).

Patients in Group $C$ had significant aortic incompetence and showed a reduction in heart volume after operation.

Thus, one year after operation the heart volume had returned to normal in 15 patients, but 10 were left with residual cardiac enlargement and a heart volume of more than $500 \mathrm{ml} . / \mathrm{m} .^{2}$ Four of these had mitral valve disease: 2 had mitral stenosis and the large heart was due to left atrial enlargement (Fig. 7); 2 had mitral incompetence and left atrial and ventricular enlargement (Fig. 8). These 4 patients still had symptoms (shortness of breath), and in the latter 2 the symptoms and left ventricular enlargement were out of keeping with the degree of mitral incompetence, suggesting that an additional myocardial factor was responsible. They had the largest post-operative heart volumes. One died suddenly a week after review, thus leaving 6 patients. One had severe systemic hypertension responsible for residual left ventricular enlargement; another had mild aortic incompetence; two had angina pectoris : coronary emboli were demonstrated in one at necropsy, but the other had normal coronary arteries on post-operative coronary arteriography. The remaining 2 patients had severe aortic incompetence with the largest hearts before operation, and still had symptoms at the time of review, but the heart volume had decreased and further regression may occur.

Mild left atrial enlargement was more difficult to assess and the minor degree of improvement after operation could not be analysed in detail.

Twenty-one patients had interstitial oedema before operation and 6 of these had B lines of Kerley. 


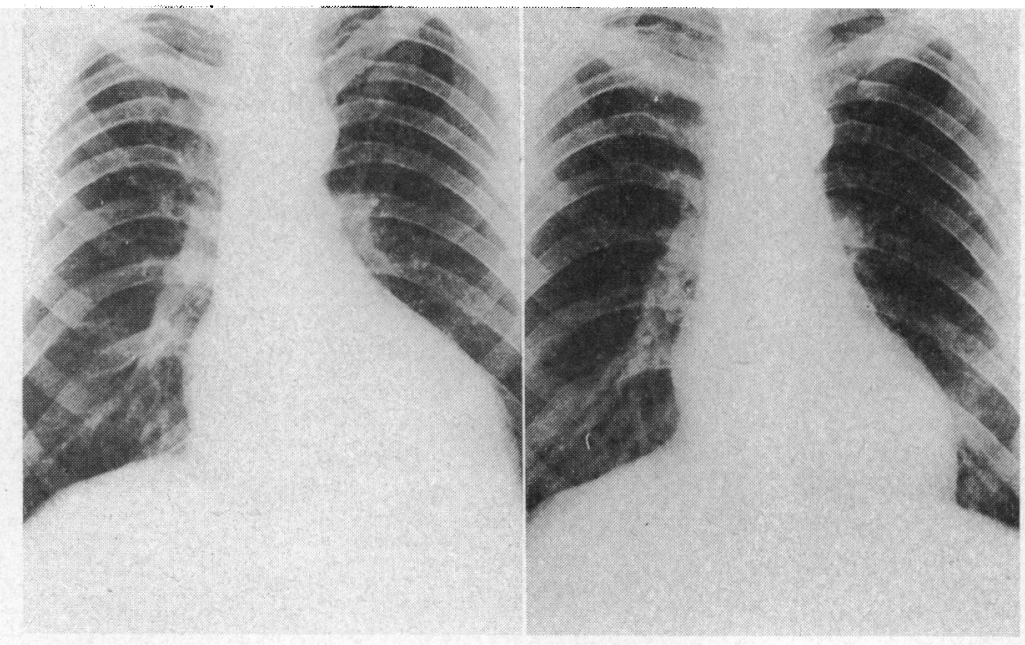

(a)

(b)

FIG. 3.-Valve replacement in an average case of aortic incompetence. A 24-year-old man with grade 4 symptoms before operation, and with a previous episode of subacute bacterial endocarditis. (a) Before operation. Large heart (volume $=650 \mathrm{ml} . / \mathrm{m}^{2}{ }^{2}$ ) with dilated left ventricle and aorta. Prominent upper lobe pulmonary veins. (b) One year after valve replacement. Patient still has residual symptoms but the left ventricular end-diastolic pressure has decreased to $10 \mathrm{~mm}$. $\mathrm{Hg}$. Heart and left ventricle are now much smaller (volume $475 \mathrm{ml} . / \mathrm{m}^{2}$ ). Aorta is smaller but still prominent. Upper zone pulmonary veins not prominent.

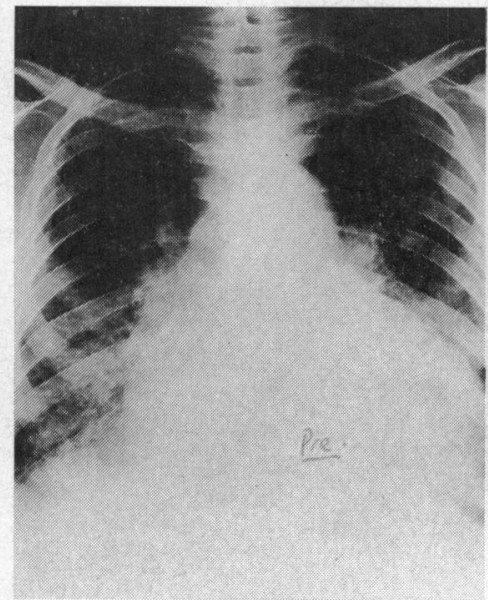

(a)

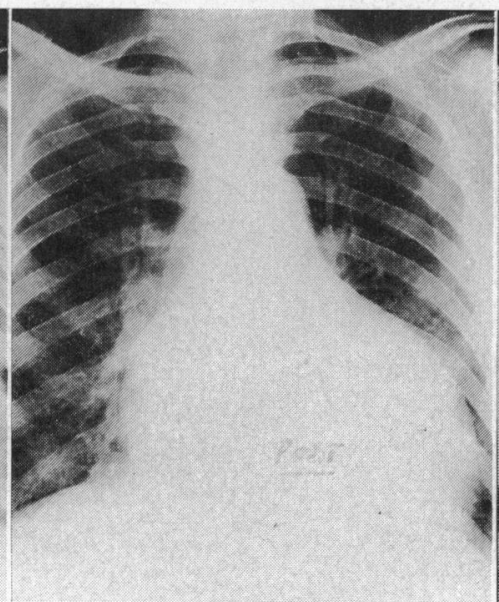

(b)

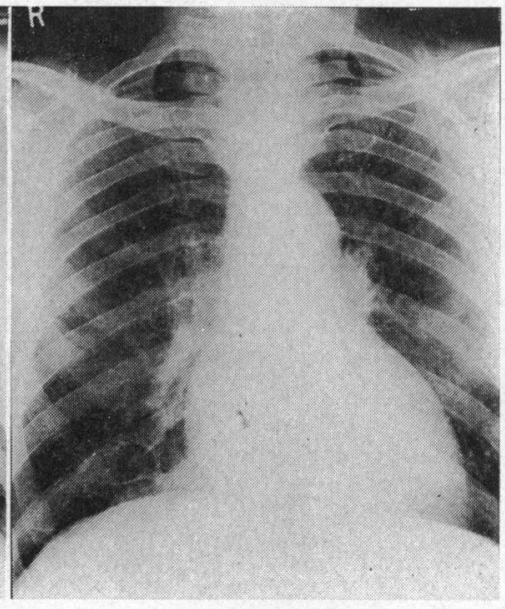

(c)

FIG. 4.-Chronological improvement in cardiac enlargement and pulmonary parenchymal changes. A 30year-old man admitted moribund; gross congestive heart failure from severe syphilitic aortic incompetence. (a) Immediately before operation. Patient had already lost $18 \mathrm{~kg}$. (40 lb.) weight from a massive diuresis following intensive medical treatment. ( $\mathrm{LV}$ end-diastolic pressure $=50 \mathrm{~mm}$. $\mathrm{Hg}$ ). Gross cardiomegaly (heart volume $=1210 \mathrm{ml} . / \mathrm{m}^{2}$ ). Interstitial pulmonary oedema and B lines of Kerley. Generalized aortic enlargement. (b) One month after emergency valve replacement. Heart and left ventricle are smaller. Interstitial oedema and prominent upper zone veins are still present but the changes are resolving. (c) One year later. Patient still slightly incapacitated (grade 2). Heart still enlarged (volume $660 \mathrm{ml} . / \mathrm{m} .^{2}$ ) but much smaller than before. Left ventricle involuting and the interstitial pulmonary oedema has disappeared.

Upper lobe pulmonary veins are still prominent. Further improvement anticipated. 


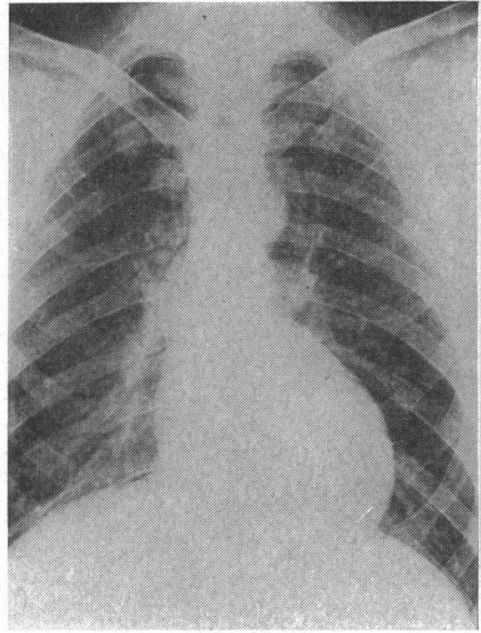

(a)

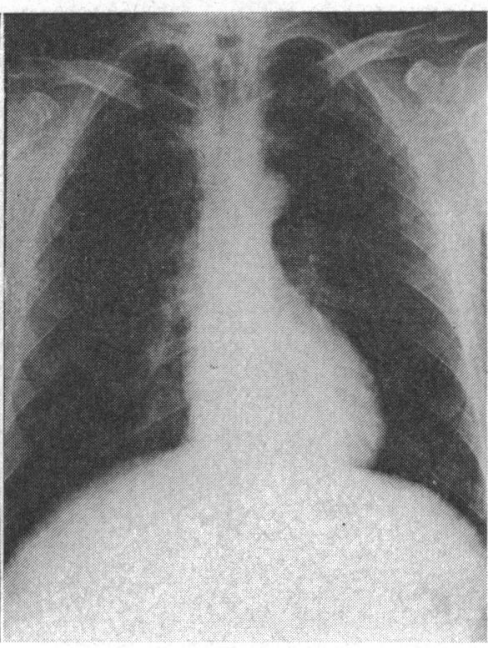

(b)

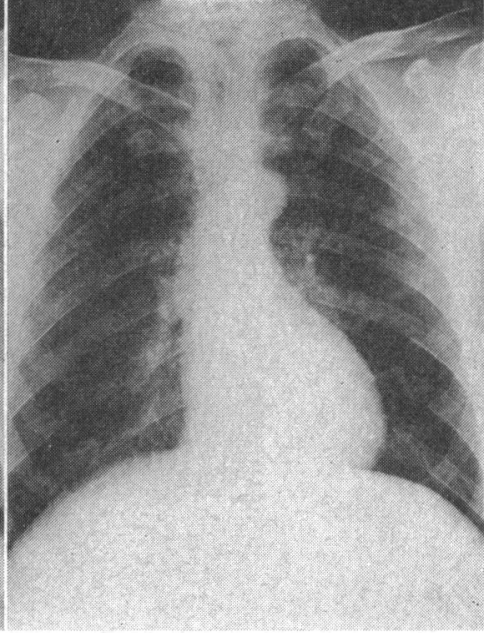

(c)

FIG. 5.-Valve replacement in aortic stenosis. A 43-year-old man with calcific aortic stenosis and grade 4 disability. (a) Before operation. Rounded, hypertrophied left ventricle; post-stenotic dilatation of the aorta with angulation of the ascending aorta; prominent upper lobe pulmonary veins (heart volume 475 $\mathrm{ml} . / \mathrm{m}^{2}{ }^{2}$ ). (b) One year after operation. Heart much smaller (volume $=380 \mathrm{ml} . / \mathrm{m} .{ }^{2}$ ) but left ventricle still prominent and post-stenotic dilatation of the aorta persists. Pulmonary venous hypertension has improved. (c) Five years later. Little change in cardiac configuration.

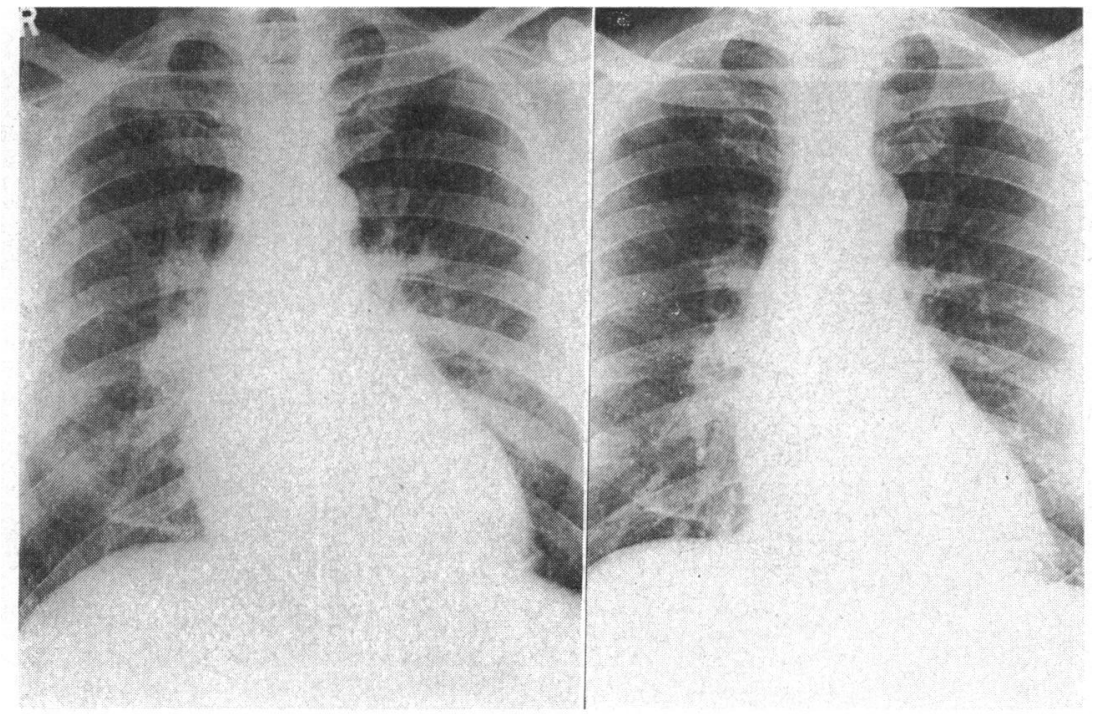

(a)

(b)

FIG. 6.-Valve replacement in aortic stenosis. A 63-year-old man with calcific stenosis complaining of angina pectoris, syncope, and grade 3 disability. (a) Before operation. (Peak systolic gradient across the valve $=115 \mathrm{~mm}$. $\mathrm{Hg}$, left ventricular end-diastolic pressure $30 \mathrm{~mm}$. $\mathrm{Hg}$ ). Heart slightly enlarged (volume $=690 \mathrm{ml} . / \mathrm{m}^{2}$ ) with a large left ventricle and post-stenotic dilatation of the aorta. Pulmonary venous hypertension with interstitial oedema due to left ventricular failure. Distended upper zone pulmonary veins seen clearly. (b) One year after operation. Heart is much smaller (volume $=520 \mathrm{ml} . / \mathrm{m} .{ }^{2}$ ); pulmonary venous hypertension has improved but aortic prominence remains. (Patient has trivial residual aortic incompetence.) 


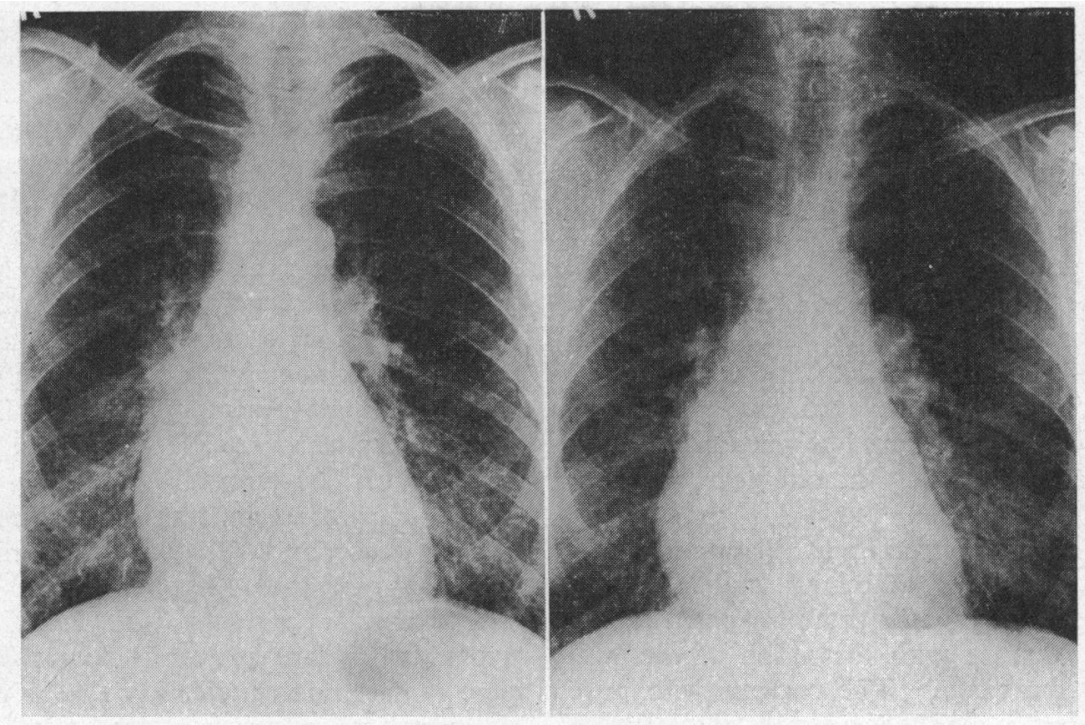

(a)

(b)

Fig. 7.-Residual mitral stenosis. A 55-year-old woman with aortic stenosis and incompetence in atrial fibrillation. Mitral valvotomy performed at the same time as aortic valve replacement. (a) Before operation. Moderate cardiac enlargement (volume $=745 \mathrm{ml} . / \mathrm{m} .{ }^{2}$ ), with slight enlargement of the left atrium and ventricle. Marked pulmonary venous hypertension and interstitial oedema. (b) One year after operation. Patient now has signs of mitral restenosis. Heart remains enlarged $\left(710 \mathrm{ml} . / \mathrm{m} .^{2}\right)$ due mainly to a prominent left atrium. Interstitial pulmonary oedema and B lines of Kerley persist.

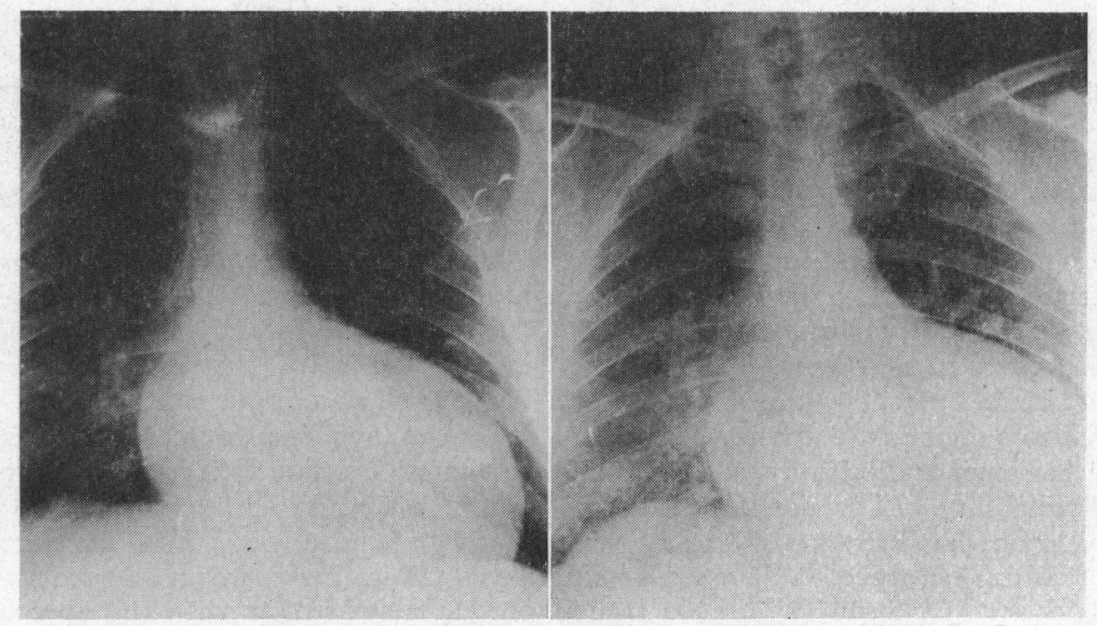

(a)

(b)

FIG. 8.-Increase in heart size after operation. A 35-year-old man with grade 4 disability before operation. Residual myocardial damage after operation. (a) Before operation. Gross cardiomegaly (heart volume $\left.=800 \mathrm{ml} . / \mathrm{m}^{2}\right)$. Left ventricular enlargement out of keeping with the degree of aortic incompetence. Patient not investigated pre-operatively. (b) One year after operation. Grade 3 symptoms, but now has an apical pansystolic murmur of mitral incompetence. Heart is larger than before with severe pulmonary venous hypertension. Patient died suddenly at home one week later. 
After operation, residual interstitial oedema was observed in 5 patients and Kerley's B lines in 2. The 2 latter patients had mitral valve disease; of the other 3, one had hypertension, one had carcinoma of the stomach, and the cause in the third patient is uncertain.

Twenty-three patients had distension of the upper zone pulmonary veins before operation. Nine had persistent distension after operation. Four of these had mitral valve disease, 3 had residual enlargement of the left ventricle, and there was no obvious cause in the other 2 . It is possible that in the latter 2 the non-compliant left ventricle had not involuted adequately during the one-year period of follow-up.

All the patients had prominent dilatation of the aorta before operation (Jarchow and Kincaid, 1961). None of the present group of patients had primary aortic disease with dissection of the wall and aortic incompetence. The patients with pure aortic incompetence had generalized dilatation of the ascending aorta and arch. This decreased in size but did not return to normal. In the 3 patients with syphilitic incompetence associated aortitis probably was present. Patients with pure stenosis had typical post-stenotic dilatation with angulation of the ascending aorta from the high velocity jet (Fig. 5) (Gotsman, 1964). This was less prominent after operation, but also did not return to normal.

\section{Discussion}

Our results show that heart volume decreased after operation in patients who had large hearts and a large volume load before operation. Improvement was a gradual process, starting immediately after operation, continuing during the following year, and with further regression possible during the subsequent years. Failure to return to normal was due to associated mitral valve lesions, coronary artery disease, or persistent aortic incompetence. No cause was obvious in 2 patients-they had the largest hearts before operation, they ejected the smallest fractions of their end-diastolic volumes at pre-operative cine-angiocardiography, and still had slight residual disability. It is possible that the period of surveillance has been too short and that further involution can be expected. Rastelli et al. (1966) and Björk and Cullhed (1967) have made similar observations after aortic valve replacement but have not analysed their radiological information in great detail.

Our results indicate that the hypertrophied dilated heart of aortic incompetence is capable of returning to a normal size when the aortic incompetence is corrected and another lesion is not present. Conversely, if the heart is persistently enlarged after operation, another anatomical cause must be sought or primary myocardial disease suspected. Lewis et al. (1966) also noted that after aortic valve replacement with a Starr-Edwards prosthesis, patients in whom the heart size returned to normal were usually without symptoms, whereas patients with persistent cardiomegaly usually had mild symptoms.

We have since seen one other patient who had persistent left ventricular failure and cardiomegaly after operation. Haemodynamic studies confirmed the presence of severe left ventricular failure and a very low cardiac output. At necropsy, there was no evidence of serious mitral valve or coronary artery disease, and the major abnormality was a dilated, hypertrophied left ventricle. We have also had 2 similar patients with heart failure and myocardial disease (proven at necropsy) after mitral valve replacement, indicating that occasionally the left ventricular myocardium may be severely damaged so that valve replacement will produce only limited, short-term benefit. Smith (1967) has made similar observations after homograft replacement of the aortic valve and attributed some of these abnormalities to obstruction of the smaller, mural coronary arteries.

All our patients had haemodynamically proven left ventricular failure or diminished ventricular compliance before operation, with raised end-diastolic pressure in the left ventricle. They showed radiological evidence of pulmonary venous hypertension, which correlated well with the rise in end-diastolic pressure. Although the prosthetic aortic valve is slightly stenotic, post-operative haemodynamic studies have shown that many patients have near normal left ventricular function and end-diastolic pressure after operation, though there are notable exceptions (Beck et al., 1966; Ross et al., 1966). This is in keeping with our findings. Persistent radiological evidence of pulmonary venous hypertension was present only in patients with associated lesions, and in the 2 patients with residual cardiomegaly and no obvious cause.

The minor improvement observed in aortic configuration is interesting. The heart is a muscular pump, while the aorta, in contrast, is an elastic capacitance reservoir. The muscular pump, relieved of its haemodynamic burden, returned to normal more readily than the over-stretched and possibly permanently damaged aortic wall. The pattern of blood flow around the lenticular prosthesis is quite different from the narrow, high velocity jet of aortic stenosis, or the diffuse, vigorous, expansile pulsation observed in aortic incompetence. Thus, the deformity persisted though the original 
deformation stresses had been removed. In 3 patients the residual abnormality was probably due to luetic aortitis.

\section{SUMMARY}

The changes in the chest $x$-ray film were studied in 25 patients, before and one year after aortic valve replacement, with the University of Cape Town lenticular prosthesis, and provided valuable information about the results of operation. The patients were divided into subgroups according to the nature of the aortic valve disease.

Heart volume and cardiothoracic ratio returned to normal in 15 patients, and the greatest improvement was observed in the patients with aortic incompetence. The causes of residual cardiomegaly are discussed.

Pulmonary venous hypertension was present in nearly all the patients before operation. Nine had persistent changes and the causes are discussed.

Improvement in aortic size and configuration was less dramatic. Much of this abnormality may be irreversible.

We wish to thank the Medical Staff of Groote Schuur Hospital for their co-operation in referring their patients, and Dr. J. G. Burger, the Medical Superintendent, for permission to publish our data. Our special thanks are due to Dr. R. P. Hewitson who performed some of the operations and Mrs. M. White for secretarial assistance. The City Council of Cape Town and the Council for Scientific and Industrial Research have provided continued financial support.

\section{REFERENCES}

Bahnson, H. T., Spencer, F. C., Busse, E. F. G., and Davis, F. W., Jr. (1960). Cusp replacement and coronary artery perfusion in open operations on the aortic valve. Ann. Surg., 152, 494.

Bailey, C. P., Glover, R. P., O'Neill, T. J. E., and Ramirez, H. P. R. (1950). Experiences with the experimental surgical relief of aortic stenosis. f. thorac. Surg., 20, 516.

Barnard, C. N., Schrire, V., and Goosen, C. C. (1963). Total aortic valve replacement. Lancet, $2,856$.

Barratt-Boyes, B. G. (1964). Homograft aortic valve replacement in aortic incompetence and stenosis. Thorax, $19,131$.

Beck, W., Barnard, C. N., and Schrire, V. (1966). The hemodynamics of the University of Cape Town aortic prosthetic valve. Circulation, 33, 517.
Björk, V. O., and Cullhed, I. (1967). Functional results with aortic ball valve prostheses (Starr-Edwards) followed for two to three years. Thorax, 22, 21.

Brock, R. C. (1954). Valvotomy for aortic stenosis. Brit. Heart F., 16, 471.

- (1957). Surgical treatment of aortic stenosis. Brit. med. F., 1, 1019.

Evans, D. W., and Carpenter, P. B. (1965). Errors involved in radiological heart volume determination by the ellipsoid-approximation technique. Brit. Heart f., 27 429.

Gotsman, M. S. (1964). The value of cinéangiocardiography in the diagnosis of congenital heart disease. M.D. Thesis, University of Cape Town.

—, Beck, W., Barnard, C. N., and Schrire, V. (1967). Changes in the appearances of the chest $x$-ray after a repair or replacement operation on the mitral valve. Brit. F. Radiol. In the press.

Jarchow, B. H., and Kincaid, O. W. (1961). Poststenotic dilatation of the ascending aorta: its occurrence and significance as a roentgenologic sign of aortic stenosis. Proc. Mayo Clin., 36, 23.

Lewis, R. P., Herr, R. H., Starr, A., and Griswold, H. E. (1966). Aortic valve replacement with the StarrEdwards ball-valve prosthesis. Indications and results. Amer. Heart F., 71, 549.

Liljestrand, G., Lynsholm, E., Nylin, G., and Zachrisson, C. G. (1939). The normal heart volume in man. Amer. Heart F., 17, 406.

McCord, C. W., Lui, A. H. F., Edwards, M. L., and Starr, A. (1962). Aortic valve replacement: the semi-rigid selfsealing ball valve prosthesis. Surg. Forum, 13, 213.

McGoon, D. C., and Moffitt, E. A. (1963). Total prosthetic reconstruction of the aortic valve. $\mathcal{F}$. thorac. cardiovasc. Surg., 46, 162.

Rastelli, G. C., Kincaid, O. W., and Kirklin, J. W. (1966). Heart size after isolated replacement of mitral or aortic valve. Proc. Mayo Clin., 41, 217.

Ross, D. N. (1962). Homograft replacement of the aortic: valve. Lancet, $2,487$.

- (1964). Homotransplantation of the aortic valve in the subcoronary position. f. thorac. cardiovasc. Surg., 47, 713.

Ross, J., Morrow, A. G., Mason, D. T., and Braunwald, E. (1966). Left ventricular function following replacement of the aortic valve. Hemodynamic responses to muscular exercise. Circulation, 33, 507.

Schrire, V., and Barnard, C. N. (1966). An analysis of cardiac surgery at Groote Schuur Hospital, Cape Town, for the 14 years April 1951-April 1965-Part 1. Acquired heart disease. S. Afr. med. F., 40, 279.

—, Vogelpoel, L., Phillips, W. L., and Nellen, M. (1955). Experience with mitral valvotomy at Groote Schuur Hospital, Cape Town. S. Afr. med. F., 29, 1108.

Simon, M. (1963). The pulmonary vessels: their hemodynamic evaluation using routine radiographs. Radiol. Clin. N. Amer., 1, 363.

Smith, J. C. (1967). The pathology of human aortic valve homografts. Thorax, 22, 114.

Viamonte, M., Parks, R. E. and Barrera, F. (1962). Roentgenographic prediction of pulmonary hypertension in mitral stenosis. Amer. F. Roentgenol., 87, 936. 